\title{
Jum, el indio impensable de La casa verde y de Mario Vargas Llosa
}

Andrea Cabel García

Recebido em: 28 de outubro de 2019

Aceito em: 25 de janeiro de 2020
Docente de la Universidad de Ciencias Aplicadas (UPC) y de la Universidad de Lima. Doctora y Máster en Literatura Latinoamericana por la Universidad de Pittsburgh. Sus investigaciones y artículos críticos exploran problemáticas referidas a raza e imaginarios postraza, indigeneidad, sulbalternidad, y desigualdad.

Contato: pcpeacab@upc.edu.pe Peru 
PALABRAS CLAVE: Mario Vargas Llosa; violencia; autorrepresentación; La casa verde; indígenas amazónicos.

KEYWORDS: Mario Vargas Llosa; violence; self-representation; The Green House; indigenous Amazonian.
Resumen: Este artículo es una lectura desde los estudios postcoloniales y subalternos realizados sobre La casa verde (1966), segunda novela del escritor peruano Mario Vargas Llosa. Proponemos explorar y desarrollar dos mecanismos de agencia de Jum, el cacique aguaruna: el primero es la lucha por la creación de una cooperativa indígena y el segundo es lo que consideramos un discurso del cuerpo. A partir de ambas estrategias, sostenemos que Jum descentra y sorprende a los personajes de la novela y al narrador, pues propone una autorrepresentación alejada de las tradicionales configuraciones orientalistas. Para demostrar esta hipótesis, nos centraremos en dos conceptos teóricos: lo impensable y una relectura de la desfamiliarización. Finalmente, plantearemos que la importancia novelesca y teórica de Jum radica en que, al encarnar un paradigma complejo de la indigenidad amazónica, problematiza el mero ejercicio de violencia hacia el Otro.

Abstract: This article is a postcolonial and post subaltern reading of The Green House (1966), from the Peruvian Nobel Laureate Mario Vargas Llosa. Our aim is to explore and develop two mechanisms of asency of Jum, the aguaruna chief. These mechanisms can be observed in two specific moments: in his battle for the stablishment of a cooperative, and in what we call "body speech". This paper contends that Jum decenter and surprise the storyteller and the characters because he proposes an alternative indigenous representation that overcomes the traditional representation, usually Orientalized of the indigenous people. To demonstrate it, we focus on two theorical concepts: the unthinkable and critical re-reading of "defamiliarization". Our main objective is to demonstrate that Jum embodies a complex paradigm of Amazonian indigeneity that seeks to problematize the violence towards the Amazonian indigenous people. 


\section{INTRODUCCIÓN}

De manera general, este ensayo es un intento de problematizar la violencia hacia los ciudadanos amazónicos peruanos. De modo particular, esperamos contribuir con el debate sobre la presencia de los sujetos indígenas en las obras del Nobel peruano, Mario Vargas Llosa, a través de un análisis de la compleja agencia de Jum, el curaca aguaruna protagonista de una de las cinco tramas de la La casa verde. Vale señalar que nuestra propuesta es una lectura de la novela desde las herramientas y la perspectiva de los estudios postcoloniales y desde los estudios subalternos. De ahí que entendamos la agencia - concepto clave en nuestra propuesta- como la posibilidad de desafiar el problema de la voz y de la representación de un sujeto que ha sido subalternizado por otro que se autonombra como "superior". Al respecto, queremos enfatizar que nuestro interés en los estudios subalternos no implica un estudio sobre la reivindicación de la representación del subalterno, ya que creemos con Beverley (2004), que estos tratan, en cambio, "de cómo el saber que nosotros producimos e impartimos como académicos está estructurado por la ausencia, dificultad o imposibilidad de representación del subalterno. Esto es reconocer, sin embargo, la inadecuación fundamental de ese saber y de las instituciones que lo contienen" (53-71). Aspiramos pues, al uso de estas herramientas -y perspectiva- teórica para pensar en un orden social más democrático e igualitario.

En esta línea, definimos la subalternidad como "un concepto relacional que consiste en un acto performativo en el que los sujetos se representan a sí mismos poniendo énfasis en las relaciones de poder en las que se encuentran 
inscritos" (Vich, 2010, 51). Al respecto, Rajanit Guha y Jacques Lacan coinciden en que "la categoría que define la identidad o 'voluntad' del subalterno es la negación” (apud Beverley, 2004, 54). Esta aproximación es relevante, puesto que el protagonista en el que nos centramos niega el olvido, niega el paso del tiempo, niega ser parte de dinámicas de poder en las que es entendido como un sujeto sin posibilidad de autorrepresentación.

Así las cosas, esta novela, reconocida ampliamente por la crítica como un "quipu literario", un "poliedro de miradas y de voces", una "polifonía coral” (Valles, 2015) o, como poéticamente señalaría Cortázar (apud Letras Libres, 2007), "una complejísima estructura musical", es también una de las pocas obras del Nobel peruano en la que los indígenas amazónicos resaltan por su valentía y su abierta lucha contra la injusticia. Por esto, la complejidad de la obra no radica únicamente en su estructura -abundantemente estudiada - sino en la forma en que sus cinco tramas conversan y visibilizan la importancia del indígena amazónico. En La casa verde, Jum -inspirado y tomado de eventos históricamente documentados- es quien encarna el potencial desestabilizador de la novela y aquel en el que es palpable la agencia y la posibilidad de responder a órdenes subalternizadoras. De ahí que es a través de su historia -novelada e histórica- que proponemos analizar la importancia y algunas consecuencias de lo que hemos llamado la "desfamiliarización”, un potente concepto teórico que necesita de lo que el sociólogo haitiano Michel Rolph Trouillot (1995) llamó "unthinkable" (impensable), puesto que nos permite salir de la lógica binaria que encapsula la identidad subalterna. O, dicho de otro modo, nos permite tener una lectura más 
amplia y compleja en la que el subalterno perturba, y reta las dinámicas de sujeción en las que se le intenta insertar.

$\mathrm{Al}$ respecto, es necesario subrayar que nuestro análisis no se sostiene en el nexo entre la novela y sus circunstancias históricas; tampoco, por ende, entre lo que está representado y quien lo representa. Seguir ese camino sería retroceder en el tiempo y referirse a un Mario Vargas Llosa que ha cambiado ideológicamente ${ }^{1}$. Por ello, lo que postulamos es un mecanismo inverso al trabajado por los estudiosos que plantean la vinculación mencionada (entre ellos Morańa, 2013, y Vich, 2002): proponemos disociar lo representado de quien lo representa, y centrar la atención únicamente en la potencia de lo representado. Después de todo ¿̨no es una lectura (re)subalternizadora omitir o cercenar la participación y relevancia de los indígenas amazónicos en esta novela? Creemos que su relectura es urgente, puesto que, en el contexto actual de violencia brutal hacia la Amazonía, un cambio en las

1 En su libro Principios comprometidos (2013), el catedrático Jorge Valenzuela agrupa tres momentos políticos en los que Mario Vargas Llosa mostró un pronunciamiento claro. En el primer y segundo capítulos, analiza a Mario Vargas Llosa en los años 60 cuando recibe el Premio Rómulo Gallegos en Venezuela mientras que ese país era controlado por un gobierno de derecha y Cuba vivía la experiencia del bloqueo norteamericano. Luego, Valenzuela aborda El pez en el agua, las memorias que el Nobel peruano escribió a partir de la derrota sufrida en el Perú en las elecciones generales a la presidencia en 1990. Y, finalmente, examina el debatido cambio de posición de Mario Vargas Llosa que terminó por justificar, en 2003, la invasión norteamericana a Irak. Como es notorio, el Vargas Llosa de los años 60 poco tiene que ver con el intelectual del 2003. Al respecto, puede contrastarse este cambio de perspectivas en el novelista a partir de una entrevista que le hiciera Maynor Freyre en el año 69 (Coaguila, 2010, 48). También, el cambio ideológico y político del Nobel puede verse en la pregunta que planteara Carlos Iván Degregori respecto de la obra que abordamos, cito: “¿cómo el autor que pudo representar un mundo tan complejo social y culturalmente en La Casa Verde es el mismo que en su campaña electoral maneja el tema de la modernidad de una manera naïve y extremadamente simplista?" (74). 
representaciones puede permitir reelerlos como parte de una comunidad que los ha excluido de su discurso e historia. Entonces, sostenemos que, a partir de la desfamiliarización, y de sus consecuencias, se puede -al menos potencialmente-, encontrar otro camino para cambiar las representaciones de los amazónicos. Una parte de este camino es, por ejemplo, confrontar al narrador -potencial voz del autor- con la sorpresa, el desequilibrio, o diríamos, lo "impensable".

\section{PropuESTA: LA DESFAMILIARIZACIÓN Y LO IMPENSABLE EN LA CASA VERDE}

La desfamiliarización, centro de nuestra propuesta teórica, es un concepto que, aunque comparte su nomenclatura con la utilizada por los formalistas rusos para referirse a la desautomatización de la percepción, en nuestra redefinición implica un doble movimiento que excede la singularización que, para los rusos, daba el arte, la lengua poética. Permítaseme explicar con más detenimiento este concepto desde "El arte como artificio" del pensador Viktor Shklovski, para, luego, contrastar con mayor detalle nuestra redefinición. Para él, "los objetos percibidos, muchas veces comienzan a serlo por un reconocimiento: el objeto se encuentra delante nuestro, nosotros lo sabemos, pero ya no lo vemos. Por este motivo no podemos decir nada de él" (Shklovski, 2013, 5, énfasis mí). En este contexto de "acostumbramiento" perceptivo, el arte posee mecanismos discursivos que liberan la mirada, ya que permiten que el sujeto desautomatice su percepción sobre los objetos cotidianos. Así, para los rusos, la "desfamiliarización" o extrañamiento era 
el proceso por el cual el arte, la lengua poética (como lo llamaría Aristóteles) tenía el poder de sorprender, de permitir que lo conocido se vuelva desconocido, nuevo. En palabras del crítico Camilo Fernández Cozman: "[La desfamiliarización] es como si el receptor viera todo por primera vez y los objetos se le tornasen extraños, aunque en la experiencia cotidiana los haya visto innumerables veces" (comunicación personal, 19 de diciembre, 2019). Fernández coincidió con Shklovski sobre la descripción del concepto y el ruso ilustra esta definición con varios ejemplos tomados de diversas obras literarias. Uno de ellos lo desarrolla a partir de la Historia de un caballo, de Tolstoi. En esta pieza, el protagonista y narrador es un caballo que, sin duda, desfamiliariza al lector. Permítasenos leer un fragmento de dicha Historia citado por Shklovski (2013):

Comprendí muy bien lo que decían acerca de los azotes y del cristianismo. Pero quedó completamente oscura para mí, por aquel entonces, la palabra su, por la que pude deducir que la gente establecía un vínculo entre el jefe de las caballerizas y yo. Entonces no pude comprender de modo alguno en qué consistía aquel vínculo. Solo mucho después, cuando me separaron de los demás caballos, me expliqué lo que significaba aquello. En esa época, no era capaz de entender lo que significaba el que yo fuera propiedad de un hombre. Las palabras mi caballo, que se refería a mí, a un caballo vivo, me resultaban tan extrañas como las palabras: mi tierra, mi aire, mi agua. (5).

Tolstoi ha conseguido que "escuchemos" las reflexiones de un caballo sobre un tema particular: la interpretación de la posesión (representada en los pronombres posesivos) para los humanos. Y más aún, cómo estas son usadas para caracterizar lo que tiene vida, como él mismo. Es por esta reflexión que el caballo de Tolstoi es único. No se parece a ningún otro y desafía 
las características más generales de este animal. Es por esto que Tolstoi ha conseguido desfamiliarizarnos de la percepción "acostumbrada" o, digamos, "automática" que cualquiera de nosotros tendría de estos animales. Sucede lo mismo en La metamorfosis de Franz Kafka, en la que no estamos viendo a un insecto cualquiera, sino a uno absolutamente singular y diferente de cualquier otro. En palabras de Camilo Fernández Cozman: "El lector tiene experiencias previas que han automatizado su percepción porque el escarabajo o la cucaracha se le asocian a él con ciertos hechos. Pero el hombre-animal en el relato de Kafka hace que el lector vea un escarabajo o cucaracha por primera vez" (comunicación personal, 19 de diciembre, 2019). Así las cosas, desfamiliarizar, tal como lo postulan los formalistas rusos, implica la posibilidad de sorprender al lector presentándole algo conocido como desconocido, como extraño, siempre, a través de un lenguaje elaborado, artístico.

La relectura que ofrecemos de este concepto mantiene la relevancia de la sorpresa, del extrańamiento frente a lo conocido visto como algo totalmente novedoso y distinto. No obstante, nuestra definición no se concentra en la elaboración de un lenguaje artístico que únicamente deshabitúe la percepción de algo, sino que la entendemos como la posibilidad de releer de un modo más "completo" a sujetos con características que han sido omitidas o distorsionadas - posiblemente- con intenciones pseudo civilizatorias o subordinantes. Por ello, la definimos como un esfuerzo por de-occidentalizar la perspectiva que establece un marco tutelar con los indígenas y aprehende su alteridad desde un panorama regido por la diferencia colonial. Esta última categoría no solo alude a un sistema discriminatorio y productor 
de subalternidades, sino que es un "espacio en el que se está verificando la restitución del conocimiento subalterno y está emergiendo el pensamiento fronterizo (...) una fuerza potente (...) capaz de desplazar al conocimiento hegemónico desde la perspectiva del subalterno" (Mignolo, 2000, ix-x). En ese sentido, la desfamiliarización que propongo es un mecanismo que visibiliza la diferencia colonial desde su revés: expone la agencia del que no se resigna a ser visto como subalterno.

Con todo esto, lo que desfamiliariza es aquello que nos propone recursos que desafían los marcos de control ${ }^{2}$, de dominio, de conocimiento y saber. En ese sentido, abre un espacio para que el sujeto no occidental -indígena, en este caso- pueda ser coherente al mismo tiempo que diferente e igual. En ello, rescato el principal valor y ventaja de nuestra propuesta sobre esta categoría: creo que revelar las desfamiliarizaciones de los sujetos indígenas es una forma de proponer un cambio en la mirada hacia ellos para instalar otra forma de entender sus muestras de agencia. Con este abordaje, busco también identificar en ese Otro -el llamado subalterno- a un sujeto que problematiza, pero que simultáneamente ofrece alianzas y luchas por los mismos objetivos del sujeto letrado y usualmente nombrado como "blanco" (o “Uno").

2 Gonzalo Lamana (2008) postuló este concepto combinando el aporte de dos críticos: Guha y De Certau. Del primero, recogió su análisis sobre la prosa de la contra insurgencia y se enfocó en las maneras en que la otredad es desplazada. Del segundo, tomó las faltas en el discurso (“faults in the discourse of comprehension") en su trabajo sobre las narrativas de los viajeros franceses. De esta intersección conceptual, Lamana afirmó que el control significaba que la alteridad aparecía en forma de flashes o shapshots y era borrada por los narradores. Un fenómeno similar ocurre con Jum en La casa verde. 
El segundo centro teórico de nuestra propuesta, y que contribuye a la existencia del primero, es lo impensable (unthinkable), un concepto acuñado por Trouillot (1995) a raíz de la invisibilización absoluta de la revolución haitiana. Trouillot señala que incluso mientras esta revolución sucedía, el resto del mundo no podía pensarla y menos comprenderla. Por ello, lo que se hizo fue borrarla de todas las fuentes (i.e libros de historia, enciclopedias, debates, etc.) y convertirla en un no-evento. El contrapeso a la eliminación de este suceso fue la enarbolación de otro: la Revolución francesa. Ella se convirtió en el gran acontecimiento representativo de la libertad, la igualdad y la fraternidad, a tal punto que obliteró completamente lo desencadenado en Haití. Trouillot planteó que la necesidad de eliminar la agencia de los esclavos haitianos para brindar un total protagonismo a la revolución "occidental" pone de relieve que lo verdaderamente impensable no era solo pensar de otro modo a los haitianos, sino que Occidente pudiera pensarse en otros términos.

Con todo esto, propongo releer La casa verde a partir de dos movimientos: visibilizar lo impensable y analizar sus consecuencias. Entiendo por estas sobre todo dos mecanismos en los que se manifiesta la desfamiliarización: la sorpresa del narrador y -lo que hemos llamado- el discurso del cuerpo de Jum. Ahora bien, el curaca aguaruna es el personaje que mejor encarna lo impensable ${ }^{3}$, no solo por sus características ficcionales (líder, emprendedor, empresario), sino también por el sustrato histórico

3 Considero que también Bonifacia es otro de los personajes de La casa verde que puede ilustrar este concepto. He teorizado al respecto en el capítulo quinto de mi tesis doctoral. Véase Cabel (2017). 
en que se fundamenta. El Jum que presenta la novela que analizamos complejiza en dos niveles la interpretación de esta: por un lado, cuestiona la postura anti indígena otorgada a Vargas Llosa por una gran parte de la crítica (López-Calvo, 2010; Martínez, 2008; Ubilluz, 2009; Vich, 2002; también los comentarios antivargasllosianos del Primer Congreso de Internacional de Narrativa Peruana ${ }^{4}$ ); y por otro lado, problematiza, desfamiliariza al mismo narrador.

En esta línea, quisiera subrayar que el aporte de este ensayo radica en que propone una forma de salir de las lógicas de contención y control que maniobra la retórica hegemónica (muy utilizada por el Estado peruano, por ejemplo). Sorprender, desestabilizar: estos son los procedimientos con los que se puede ayudar a repensar con más cuidado la violencia hacia los indígenas amazónicos. Asimismo, aunque ha sido señalado que "la verdad, en una ficción es fundamentalmente estética para Vargas Llosa (...); sin embargo, este hecho (...) no la aleja, simultáneamente de sus responsabilidades trascendentes" (Valenzuela, 2017, 82). Es decir, no la aleja de las posibilidades de vivir y ser otros, o, en términos de Iser, "extendernos a nosotros mismos" (Valenzuela, 2017, 83).

4 En La revancha de la imaginación (2008) se recupera a modo de crónica algunas declaraciones emitidas en el evento. Siguiendo a Carlos Granés, autor de la publicación, "para Mario Vargas Llosa todo lo que no sea occidental es barbarie" (21). Por su parte, Dante Castro señala que "si Mario Vargas Llosa hubiera ganado las elecciones, hubiera cambiado el escudo nacional por una esvástica” y "qué se puede esperar de alguien que exculpó a los militares por la matanza de Uchuraccay” (21). La mayor parte de críticas que reúne Granés es sobre Lituma en los Andes, la novela aparentemente más odiada por los antitelúricos. 


\section{Primera parte: Jum, IMPENSABLE}

Comienzo por señalar que la cooperativa indígena que funda y defiende el curaca Jum es también impensable por los personajes de la obra. Entiéndase con esto, por los caucheros, los soldados, el gobernador de Nieva, y, en general, por cualquiera que juzgue desde la diferencia colonial (i. e. exotizada y tutelarmente) a los aguarunas. La razón para afirmar esta idea es tajante: el proyecto cooperativo muestra a los indígenas como sujetos complejos, creadores de su propia autonomía, interesados en postular otra forma de pensar la nación, una forma en la que ellos se posicionan como agentes trascendentales de su desarrollo. Por supuesto, este hecho produce reacciones muy diversas. Analicemos algunas.

Desde el capítulo uno, la formación de la cooperativa aparece en boca de los soldados y socios de Julio Reátegui, gobernador de Santa María de Nieva, quien cede ese puesto para poder dedicarse cómodamente al comercio ilegal del caucho. En ese momento, todavía no han apresado a Jum.

Y Arévalo Benzas también, don Julio, se pone de pie, dejaba constancia, él había dicho detrás de esas banderas y de esas cartillas hay otra cosa y él se opuso a que los maestros vinieran, don Julio, y Pedro Escabino golpea la mesa con su vaso, don Julio: la cooperativa era un hecho, los aguarunas iban a vender ellos mismos en Iquitos, se habían reunido los caciques en Chicais para hablar de eso y ésa era la verdadera situación y lo demás ceguera. Solo Julio Reátegui no conocía un solo aguaruna que supiera lo que es Iquitos o una cooperativa, ¿de dónde habia sacado semejante historia Pedro Escabino?, y les rogaba que hablaran uno por uno, señores. (47; el énfasis es mío).

Enfatizo en esta cita el rechazo a asumir que sea posible que los indios generen ideas relacionadas con el comercio y el valor del trabajo. Más aún, 
al hecho de que se busca negar la capacidad propositiva de los indígenas descalificándolos como sujetos controlables 5 . El ejemplo que ilustra este punto lo encontramos cuando Reátegui afirma que era imposible que los aguarunas conozcan Iquitos, pues creía que ingenuamente lo confundían con un patrón. Desestimar sus reclamos, entonces, es una forma de acallar el plan de Jum. De más está anotar que la propuesta no tiene que ver con si Iquitos es o no un hombre, sino con el claro pedido de un negocio justo.

Por otra parte, vale la pena situar al asombro y a la total negación como las protagonistas de esta escena. De hecho, los hombres de Julio Reátegui intentan explicar lo siguiente:

Pedro Escabino sabía cuánto le debían y no quería ofenderlo: solo que acababa de llegar de Urakusa y por primera vez en diez años, don Julio, seco y sordo dos veces contra la mesa, los aguarunas no quisieron venderle ni una bolita de jebe, pese a los adelantos y Arévalo Benzas: hasta le enseñaron la cooperativa. (48; el énfasis es mío).

A Reátegui estas aseveraciones no le convencen. Para él no es posible que los indios sean capaces de negarse, es decir, de decidir, y menos aún, de proponer. En este gesto, no es difícil percibir que Reátegui se autoproclama Uno para subalternizar a la otra parte llamándola Otro. Después de todo, si Reátegui aceptara que Jum no es tan diferente de él, cuestionaría esa matriz de poder que salvaguarda la diferencia colonial (aquella que le

5 Para Gonzalo Lamana (2008), la palabra cultura en los contextos de contacto con una alteridad distinta es clave, ya que 'the language of 'culture' and 'custom' and the practices of intervention it legitimizes, allows imperial agents to exercise control over the clearly different and inferior Other, cajoling her or him into a given set of options enforced through politics of authenticity" (5). 
permite gobernar, abusar, torturar a través de la etiqueta de la "civilización" y el paternalismo). Sin embargo, resiste, niega e invisibiliza la desfamiliarización y prefiere la burla hacia la materialización de la cooperativa: "Don Julio, que no se riera, habían hecho una cabaña especial y la tenían repleta de jebe y de cueros y a Escabino no quisieron venderle" (48).

Es recién cuando Reátegui encara lo impensable $-\mathrm{y}$ a su consecuencia, la desfamiliarización- que su encuentro con Jum cobra sentido. Al estar frente a frente, Reátegui lo golpea con la linterna y, a modo de respuesta, Jum habla en espańol. Delante del capitán Quiroga, del cabo Delgado, entre otros, Jum dice "cooperativa". Ahora alguien a quien consideran infrahumano, carente de idioma, está proponiendo una empresa que compita, además, en el mismo código lingüístico. Todo esto es impensable y, por ello, absolutamente transgresor. Es, en términos de Bhabha (2004, X), una turbulencia feroz para la cómoda idea que se ha construido de los indígenas como subhumanos incapaces de formular proyectos, y que precisan de un tutelaje que los encarrile hacia la civilización/modernidad.

Es por este motivo que ante la respuesta de Jum ("cooperativa"), Julio Reátegui reacciona del siguiente modo:

¿Cooperativa? Esa palabra no existía en aguaruana, hijo, ¿̇le había dicho cooperativa? Y el intérprete: la había dicho en español, señor, y el capitán Quiroga sí, él había oído (...) Julio Reátegui parece abstraido, se saca el casco, se alisa los cabellos, mira al capitán... (142; el énfasis es mío).

Los lectores notamos su sorpresa. De hecho, creemos que esta es una forma de manifestar su afectación frente a un fenómeno que lo descoloca. 
A propósito, lo que hará después Reátegui será suturar -siguiendo a Bhabha (2004) - ese desconcierto inicial y restablecer su equilibrio. Así, deslegitimar el pedido es un modo de volver al único orden que conoce, aquel en el que Jum no enuncia su propia voz. Por eso, recurre también a las torturas y humillaciones. Una de ellas, por ejemplo, consiste en raparle el cabello, pues ese acto supone una fuerte degradación simbólica en el código cultural aguaruna. Se "escarmienta" a Jum para que no vuelva a hablar en español, y para que no sugiera en otra ocasión ninguna revuelta o competencia. La justicia, como el comercio, para Reátegui, se instituye entre iguales, y necesita que Jum entienda que él no es ni será su igual.

Otra clara muestra de la necesidad de suturar lo impensable ${ }^{6}-\mathrm{y}$ su consecuencia, la desfamiliarización- está descrita en el capítulo tres de la novela. Este es el segundo momento en la vida de Jum que nos interesa: Julio Reátegui ha dejado de ser gobernador y Jum carga con cicatrices y marcas de los flagelos que padeció. El intérprete no es más Bonino Pérez, sino el práctico Adrián Nieves. En ese encuentro, ya no asisten los soldados de la guarnición, sino otros, que están cansados de escuchar el reiterativo reclamo de Jum sobre lo que le robaron: los silabarios, la muchacha y las pieles.

El sargento, cansado de lidiar con él, opta por "hacer lo de siempre": desviarlo imitando una forma legal (o como encontramos en la novela: "cojudearlo en regla"). Le proporciona un "papelito firmado", una hoja

6 Entendemos que "suturar" lo impensable es equivalente, en términos de Bhabha (2004), a "suturar una turbulencia”. Explicamos esta equivalencia teórica como el intento por desestimar la sorpresa que desencaja un presupuesto y el intento por colocar las piezas nuevamente tal como son pensadas por el sujeto hegemónico. 
cualquiera garabateada, y piensa que con eso, con apelar al valor de lo escrito, lo va a calmar:

Le iban a devolver el jebe, las pieles, los silabarios, la muchacha, todo lo que quisiera, y el Pesado qué le pasaba, mi sargento, quién le iba a devolver si Escabino ya era difunto, y el Chiquito ¿¿no sería de sus sueldos, no?, y el sargento para más seguridad le darían un papelito firmado. Ya lo habian hecho alguna vez con el teniente Cipriano, mi teniente, daba resultado. Le pondrían una estampilla en el papel y listo: ahora anda a buscar con eso al señor Reátegui y al Escabinodiablo para que te devuelvan todo. Y el Oscuro ¿una cojudeada en regla, mi sargento? Pero al teniente no lo convencian esas cosas, él no podía firmar ningún papel sobre este asunto tan viejo, y él además, pero el sargento papel periódico no más, una firmita de a mentiras y así se iría tranquilo. Estos eran tercos, pero creían lo que se les día, se pasaría meses y años buscando al Escabino y al señor Reátegui ... (177; el énfasis es mío).

Jum recibe "una firmita de a mentiras", pero su respuesta es ejemplar. Él nota el engaño y comprende que no puede negociar ni reclamar a personas que no lo toman en cuenta, que no lo quieren escuchar, y que ven en él una idea arbitraria y no lo que realmente es. Por ello, el capítulo acaba con Jum cogiendo el papel y retirándose para romperlo en el camino. Este gesto es muy relevante, puesto que el narrador se encarga de que otro personaje lo atestigüe:

Un perro flaco pasa junto a él y el oficial sigue con la vista y entonces ve al práctico Nieves. Viene hacia él y le muestra en su mano los pedacitos blanquinegros de papel periódico, teniente: no era tan cojudo como se creía el sargento, habia hecho trizas el papel y lo habia tirado en la plaza, el pasaba y acababa de encontrarlo. (178; el énfasis es mío). 
Tal como hace muchos años, Reátegui se sorprendió cuando escuchó que Jum le decía cooperativa en espańol; ahora los soldados se asombran al ver que Jum, aceptando el papel firmado, había seguido el juego que ellos habían propuesto para no alterar lo que pensaban de él. En otras palabras, Jum había simulado ser lo que ellos necesitaban que sea. Es su capacidad de simulación lo que invierte la idea de que es sencillo embaucarlo. Además, su acto comprueba que eran ellos los más fáciles de ser engañados, acentuando lo impensable y el efecto desfamiliarizador.

Si analizamos de cerca la actitud y la acción de Jum, notamos que él sabe cómo comportarse para que ellos se sientan seguros: sabe fingirse un "salvaje" que acepta un papel periódico garabateado como si fuera un contrato. Sabe fingirse ignorante, confiado, débil. No obstante, está claro que puede aparentar ser "salvaje" precisamente porque no lo es. En ese sentido, encarna lo que W. Du Bois ha denominado doble consciencia ${ }^{7}$ él puede performar lo que los otros imaginan de él, pero con la consciencia de ser distinto de ello. Lanzar el papelito es el fin del juego en el que Jum actúa como lo que sabe que piensan de él. Entonces, lo desfamiliarizante es el efecto del gesto de deshacerse del juego; lo que lo muestra como es realmente. Finalmente, es interesante que el capítulo culmine ahí, e inmediatamente comience otro, puesto que parece subrayar la imposibilidad de sutura del gesto de Jum. Es

7 Du Bois lo definió así en su libro The souls of Black Folk (2007): "It is a peculiar sensation, this double-consciousness, this sense of always looking at one's self through the eyes of the others, of measuring one's soul by the tape of a world that looks on in amused contempt and pity. One ever feels his two-ness -An American, a Negro; two souls, two thoughts, two unreconciled trivings; two warring ideals in one dark body [...]" (2). 
decir, de alguna manera, se le representa como un sujeto que escapa a cualquier lógica de control y que no necesita ser tutelado ni aún por el mismo narrador.

\section{JUM Y EL DISCURSO DEL CUERPO}

La particularidad que asombra de Jum es su negación al silencio, es decir, su forma alternativa de mostrarse como una "antítesis necesaria" (Guha, 2002, apud Beverly, 2004) del sujeto dominante (en este caso, Reátegui, el representante del Gobierno). Por ejemplo, luego de ser torturado, Jum no elige huir. Por el contrario, pasan los años y él continúa buscando a los soldados para reclamarles lo que le quitaron en el momento de la paliza, y además decirles que lo que le hicieron es fruto de un malentendido: "Y el intérprete: yendo y viniendo, práctico escapando, urakusapatria, carajo, banderagobierno" (171; el énfasis es mío). Jum aclara que a quien deberían castigar es al práctico que les robó, y que su patria es Urakusa, su poblado. Luego, se remite a dos símbolos: la bandera y el gobierno. Si constantemente se refiere a la peruanidad, la mención al símbolo patrio y al gobierno no es casual. Jum está intentando apelar a instancias que lo albergan tanto a él como a los soldados. Sin embargo, los guardias no entienden así el mensaje y buscan ahuyentarlo.

Pero Jum no quiere irse. ¿Qué hacer con su presencia constante? Él persevera a tal punto que entre los soldados se comenta lo que sigue:

El oficial termina de anudarse los zapatos, se pone de pie. ¿Al menos era tratable? El sargento hace un gesto vago: no se ponía maldito pero, eso sí, 
la terquedad andante, una mula, nadie le sacaba lo que tenía en la tutuma ${ }^{8}$. ¿Cuándo habia sido ese lio? Cuando era gobernador el señor Julio Reátegui, antes de que hubiera una comisaría en Nieva. (171; el énfasis es mío).

Lo interesante de este pasaje es la marca temporal que delinea el carácter de Jum. El cacique insiste a través de los años, no deja de interpelar al resto sobre lo que le robaron: "Y el intérprete: la putasumadre, mi cabo, escabinodiablo, insultando” (171). Adrián Nieves, el mejor práctico, comienza a traducir a Jum más adelante: "Robando carajo, urakusajebe, muchacha, soldadomireategui, mi cabo" (173). El mensaje se mantiene intacto a lo largo de sus apariciones, más los soldados se negaban a entenderlo: "Pero el pagano lo mezclaba todo, y uno no sabía qué tenían que ver los silabarios con el jebe que reclamaba y con lo de esa muchacha, mi compadre tenía un enredo de los mil diablos en la tutuma” (173). Los soldados no querían entender lo que él decía, aunque lo repitiese año tras año, por mucho tiempo. Después de todo, para ellos, ¿cómo un "salvaje” podría tener sentido de propiedad? El discurso de Jum, que puede ser fracturado siempre busca revertir la figura de dominio de los caucheros. No deja de insultarlos ni de demostrarles que de ellos ha aprendido las palabras exactas para definirlos: malos peruanos, diablos, hijosdeputa. Pero más aún, Jum nota cuándo su discurso deja de ser útil, y elige el momento oportuno para reemplazarlo por gestos clave. Veamos por ejemplo su última participación en la novela.

8 “Tutuma” significa 'cabeza'. 
En esta parte, decide quedarse con el resentimiento y apropiarse de esa humillación: se atreve a recodarla y mostrarla, y a usar su cuerpo como vitrina para exhibir lo inhumano de su castigo. Cito in extenso:

Ahí estaba mi teniente, ése era el pagano -así les decían acá a los chunchos-y el oficial sonríe: el creía que éstos se dejaban crecer la peluca hasta los pies, no se esperaba ver a un calvito. Una menuda pelusa cubre la cabeza de Jum y una cicatriz recta y rosácea secciona su frente minúscula. Es de mediana estatura, grueso, viste una itípak raída que cae desde su cintura hasta sus rodillas. En su pecho lampiño, un triángulo morado ensarta tres discos simétricos, tres rayas paralelas cruzan sus pómulos. También tiene tatuajes a ambos lados de la boca: dos aspas negras, pequeñitas. Su expresión es tranquila, pero en sus ojos amarillos hay vibraciones indóciles, medio fanáticas. Desde esa vez que lo pelaron, se seguia pelando solito, mi teniente, y era rarísimo porque nada les dolía más a éstos que les tocaran la peluca. El práctico Nieves se lo podía explicar, mi teniente: era una cosa de orgullo. (172; el énfasis mío).

Esto es singularmente valioso puesto que Jum es el único que arriesga un camino distinto de los caucheros y, aun torturado y humillado, decide utilizar el dolor como otra estrategia de desequilibrio a los sujetos que se presentan como hegemónicos. De esa manera, interviene en su condición de dominado: ya no es más una entidad que carece de poder de autorrepresentación. Gracias al gesto de recortarse el cabello y de volverse a pintar las marcas de los azotes con achiote, que simbolizaría la sangre que corría de sus heridas, Jum se empodera y reinventa su propio cuerpo mediante el lenguaje visual del castigo. Es la consciencia de su performance (mostrar sus heridas realizando una ceremonia con ellas) lo que lo convierte en un indio impensable: 
Jum da un paso, se coloca ante el oficial, escupe (...) Se toca la cicatriz de la frente y lento, ceremonioso como un ilusionista, gira sobre los talones, exhibe su espalda: desde los hombros bajan hasta su cintura unos surcos pintados de achiote, rectilíneos, paralelos y brillantes. Ésa era otra de sus locuras, mi teniente. (176).

Lo que ellos, los soldados, llaman "locura" es lo impensable. O, dicho de otro modo, que el Otro revele conciencia crítica para desplegar una performance que privilegie la reconstrucción de la memoria personal (sus marcas) hacia la memoria colectiva (la situación de los demás indígenas masacrados y la acusación directa de los abusadores) y que delate el incumplimiento de la justicia a través del uso ritual de su propio cuerpo, todo eso es impensable. El acto de Jum excede, supera el raciocinio de los soldados; por ello, debe ser descalificado y - una vez más- controlado.

\section{CONCLUSIONES}

Los mayores problemas contra los que han luchado las comunidades amazónicas del Perú son la invisibilización y el enmudecimiento. Ambos fenómenos son parte de potentes estrategias de quienes detentan el poder. En este contexto, el trabajo de Mario Vargas Llosa en torno a los aguarunas que representa en La casa verde no deja de ser cuestionador y trascendente. Después de todo, con o sin voluntad, el Nobel se ha encargado de que el caso de Jum se conozca en todos los países del mundo a lo largo de más de 40 años. $\mathrm{Y}$ a esto habría que ańadir dos hechos que invitan a repensar la presencia de Jum como un personaje central en el universo ficcional de Vargas Llosa: 
la obsesión del autor por mencionar a su personaje en diversas entrevistas y la elección de cederle un espacio en otra obra (El hablador). Así, aunque en la realidad y en la ficción las autoridades que castigaron inmerecidamente a Jum quedaron impunes, existe una cierta "justicia novelesca" gracias a que el narrador de la novela que nos compete lo construye con una superioridad moral y una praxis ética mayor que la de sus atacantes. Los lectores vinculados con la compleja realidad social de la Amazonía podemos entender la novela desde una arista distinta: desde la empatía, la cual nos permite aprehender la imagen de un indígena que se resiste a las vejaciones y los abusos.

De otro lado, es relevante subrayar la importancia de encontrar a un Jum decididamente ético. Al respecto, el Nobel señala en su Historia secreta de una novela (1971) que cuando regresa a Nieva -seis años después de escribir La casa verde - se encuentra con el siguiente escenario:

Para ese puñado de hombres no había nada condenable en lo sucedido [la tortura de Jum]: las cosas eran así, la vida era así, Jum seguía siendo alcalde del pueblito de Urakusa y no había forma de hacerle recordar el episodio negro del pasado; nos dio la impresión, incluso, de que se sentía avergonzado y culpable de lo que le habia ocurrido. Para él y para los suyos la vida habia recobrado su atroz normalidad. (72-73; el énfasis es mío).

Es evidente entonces que, si bien el autor pudo elegir entre presentar un Jum desmemoriado y culposo, lo que nos entrega es la imagen opuesta: el Jum ficcional protesta, impreca y, finalmente, prescinde de quienes sabe que no lo van a ayudar y se marcha a buscar incansablemente otros que lo quieran escuchar. De hecho, parte hacia otra novela -trasciende textualidades-y se encuentra con el mismo "hablador". 
Una observación más. No es solo que Vargas Llosa eligió popularizar una figura de resistencia para la posteridad de Jum, sino que todos los datos que brindó sobre su maltrato (el lugar en el que se llevó a cabo, las razones, el contexto y los nombres de los responsables) son verdaderos ${ }^{9}$. Más aún, hay un detalle que vale la pena referir: Jum es impensable para los otros personajes -como Reátegui y los soldados-, para los lectores, e incluso para el mismo novelista, pues el personaje excedía las formas tradicionales en que se piensa a los sujetos de la Amazonía. Así, con el desequilibrio sembrado en el proceso de escritura, se instauró una huella desfamiliarizante que se mantuvo en la constitución final del curaca. Cito in extenso lo que comenta el Nobel:

Quizás resulte interesante el caso de un personaje que en mi plan inicial de la novela debió ser mucho más importante: Jum. Su historia está basada en un hecho real. Lo conocí en un viaje a la selva cuando aún estaba muy viva la historia de las torturas a las que lo sometieron; todavía era el personaje al que habían rapado; tenía la cicatriz del golpe con la linterna que le dio uno de los soldados que invadió su caserío. Esa historia me impresionó muchísimo y quería que apareciese en $L a$ Casa Verde, que fuese narrada desde la intimidad del propio Jum y, sin embargo, no pude conseguirlo porque en ningún momento encontré un lenguaje que me resultara persuasivo. No pude inventar a ese ser primitivo que vivía en un mundo mágico-religioso, no en uno racional y moderno; y que desde ese primitivismo vivió la experiencia de esa injusticia resultante, fundamentalmente de una confusión. Por eso en La Casa Verde la historia de Jum aparece muy fragmentada y entrevista $o$ descrita desde la perspectiva de terceros, de personajes que si podía imaginar e inventar con más comodidad. (Williams, 89; el énfasis es mío).

9 Incluso, Vargas Llosa (1971) declaró: "Me había propuesto contar en La Casa Verde, con máxima fidelidad, la historia de Jum, de la cooperativa aguaruna, del escarmiento que infligieron a Urakusa" (65; énfasis mío). 
Nos preguntamos entonces: ¿por qué inventarle una agencia que no existió? ¿Es esto realmente más "cómodo" o efectivo narrativamente? Creemos que, al estar construida la verdad de esta obra sobre experiencias de seres humanos reales, "lo que hace una ficción no es solo referir esa experiencia, haciéndonos presentes (...) sino que contribuye a ampliarla a través de canales (...) en los que, en principio, se produce una ampliación de nosotros mismos" (Valenzuela, 2017, 82). Es así que ha sido imposible trasladar la voz de Jum, no tanto por no poder imaginarla, sino porque el desconcierto inficcionalizable al que invita el autor, recupera la experiencia vital del cacique. Por todo esto, es legítimo leer en esta novela el triunfo de un descentramiento al narrador.

Así las cosas, el autor ha elegido entregarnos un Jum que responde a lo impensable, un indígena que socava los prejuicios y que nos permite alegar que La casa verde ofrece posibilidades y potencialidades de desfamiliarización a través de sus personajes indígenas. Desde nuestro punto de vista, ellos -no solo Jum- asumen lugares de enunciación complejos y, por ende, son capaces de producir prácticas simbólicas en las que es posible verlos con autonomía plena. Y es esto, finalmente, lo que nos interesa: visibilizar la potencialidad desfamiliarizadora de sujetos novelescos que retan la perspectiva normalizada. Por todo esto, como señaló José Miguel Oviedo (1970), creo que La casa verde nos permite algo más que creer: nos propone dudar. 


\section{REEERENCIAS BIBLIOGRÁFICAS}

Bhabha, Homi. The location of culture. Londres: Routledge, 2004.

Beverley, John. Subalternidad y representación. Debates en teoría cultural. Madrid: Iberoamericana, 2004.

Cabel, Andrea. La desfamiliarización del Otro y del Uno para repensar la violencia y la indigeneidad amazónica peruana. Disertación doctoral. TDSAS/UP, Pittsburgh: 2017. Disponible en http://d-scholarship.pitt.edu/33675/1/ AEGCdissertationFinal1_1.pdf

Castro-Klarén, Sara. Mario Vargas Llosa: análisis introductorio. Lima: Latinoamericana, 1988.

Coaguila, Jorge. Entrevistas escogidas a Mario Vargas Llosa. Iquitos: Tierra Nueva, 2010.

Du Bois, William Edward Burghardt. Darkwater: Voices from Within the Veil. New York: Oxford University Press, 2007.

Faverón, Gustavo. "La casa verde y las teorías alegóricas de la subjetividad latinoamericana”. In: Chasqui, 35-1, Lima: 2006, 119-132.

Granés, Carlos. La revancha de la imaginación: antropología de los procesos de creación: Mario Vargas Llosa y José Alejandro Restrepo. Madrid: Consejo Superior de Investigaciones Científicas, 2008.

Iser, Wolfgang. "La ficcionalización: dimensión antropológica de las ficciones literarias”. In: Garrido Domínguez, Antonio (comp.). Teorías de la ficción literaria. Madrid: Arco Libros, 1997, 43-65.

Lamana, Gonzalo. Domination without Dominance: Inca-spanish Encounters in Early Colonial Peru. Durham: Duke University Press, 2008.

Letras Libres. Tres cartas a Vargas Llosa. Disponible en: https://www.letraslibres. com/mexico-espana/tres-cartas-vargas-llosa. Acceso: 10. Ag. 2019. 
López-Calvo, Ignacio. “Going Native: Anti-indigenism in Vargas Llosa’s The Storyteller and Death in the Andes". In: De Castro, Juan y Birns, Nicolas (eds.). Vargas Llosa and Latin American Politics. New York: Palgrave Macmillan, 2010, 103-124.

Martínez Cantón, Clara Isabel. "El indigenismo en la obra de Mario Vargas Llosa". In: Espéculo. Revista de estudios literarios, 38, Madrid: 2008. Disponible en: https://webs.ucm.es/info/especulo/numero38/vllindig.html.

Mignolo, Walter. Local histories/Global Designs: Coloniality, Subaltern Knowledges and Border Thinking. New Jersey: Princeton University Press, 2000.

Moraña, Mabel. Arguedas/Vargas Llosa: dilemas y ensamblajes. Madrid, FrankfurtMain, Lima: Iberoamericana, Vervuert, Librería Sur, 2013.

Oviedo, José Miguel. Mario Vargas Llosa: la invención de una realidad. Barcelona: Seix Barral, 1970.

Shklovsky, Víktor. El arte como artificio. Disponible en http://www.catedramelon. com.ar/wp-content/uploads/2013/08/El-Arte-como-Artificio.pdf. Acceso en: 5. Ag. 2020.

Trouillot, Michel-Rolph. Silencing the past: Power and the Production of History. Boston: Beacon, 1995.

Ubilluz, Juan Carlos. "El fantasma de la nación cercada". In: Ubilluz, Juan Carlos; Hibbett, Alexandra y Víctor Vich. Contra el sueño de los justos: la literatura peruana ante la violencia politica. Lima: Instituto de Estudios Peruanos, 2009, 19-85.

Valenzuela, Jorge. Principios comprometidos: Mario Vargas Llosa entre la literatura y la política. Lima: Cuerpo de Metáfora, 2013.

Valenzuela, Jorge. La ficción y la libertad: cuatro ensayos sobre la poética de la ficción de Mario Vargas Llosa. Lima: Cuerpo de Metáfora, 2017.

Valles, José. “La casa verde: medio siglo de un 'quipu' literario. Lector, trama y técnicas narrativas en La casa verde de Mario Vargas Llosa”. In: Revista Signa, 
24, Madrid: 2015, 497-513. Disponible en http://revistas.uned.es/index.php/ signa/article/view/14737/13152

Vargas Llosa, Mario. La casa verde. Lima: Peisa, 1966.

Vargas Llosa, Mario. Historia secreta de una novela. Barcelona: Tusquets, 1971.

Vich, Víctor. El caníbal es el Otro: violencia y cultura en el Perú contemporáneo. Lima: Instituto de Estudios Peruanos, 2002.

Vich, Víctor. El discurso de la calle. Los cómicos ambulantes y las tensiones de la modernidad en el Perú. Lima: Red para el Desarrollo de las Ciencias Sociales en el Perú, 2010. Disponible en http://srvdspace-pub.up.edu.pe/bitstream/ handle/11354/263/VichVictor2001.pdf?sequence=5\&isAllowed $=y$

Williams, Raymond. Otra historia de un deicidio. México DF: Taurus, 2001. 
